\title{
On Macroeconomic Impact of Fishing Effort Regulation: Measuring Bottom-Up Fish Harvesters' Economy-Wide Contribution
}

\author{
Pierre Failler' ${ }^{1}$ Haoran Pan², Andy Thorpe ${ }^{3}$, Ruangrai Tokrisna ${ }^{4}$ \\ ${ }^{1}$ Centre for Economics and Management of Aquatic Resources, University of Portsmouth, Portsmouth, UK \\ ${ }^{2}$ Emerging Markets Institute, Beijing Normal University, Beijing, China \\ ${ }^{3}$ Department of Economics, University of Portsmouth, Portsmouth, UK \\ ${ }^{4}$ Department of Agricultural and Resource Economics, Kasetsart University, Bangkok, Thailand \\ Email: phr128@163.com, hrpan@bnu.edu.cn
}

Received 22 February 2014; revised 26 March 2014; accepted 11 April 2014

Copyright (C) 2014 by authors and Scientific Research Publishing Inc.

This work is licensed under the Creative Commons Attribution International License (CC BY).

http://creativecommons.org/licenses/by/4.0/

cC) (7) Open Access

\begin{abstract}
This research develops a hybrid input-output model to quantify the economy-wide impact of capture fisheries on the economy. The method regards capture fisheries to be the "carrier branches" producing "core inputs", which can drive the other fisheries sectors in the Ghosh supply-driven model. These fisheries sectors are all linked with the rest of the economy and can affect it through backward linkages in the Leontief demand-driven model. The empirical findings based on the Thai fisheries corroborate findings in other literature and further reveal that capture fisheries make a much greater contribution to the economy than is usually thought.
\end{abstract}

\section{Keywords}

Capture Fisheries, Fish Chain, Sector Linkage, Input-Output Modeling, Macroeconomic Impact

\section{Introduction}

Capture fisheries have historically been an important contributor to the coastal or island economy, particularly in developing countries, but currently concerns are expressed about the overexploitation of important fish stocks and the industry's sustainability. In order to reconcile short-run economic benefit, resource conservation, and fisheries sustainability, fisheries management and policy making need to identify heterogeneous fish harvesters' different economic contribution so that current fishing practices can be better justified and regulated.

The harvesters are bottom-up fish producers whose economic contributions are traditionally assessed in term 
of the value added, particularly profit or rent, generated at the microeconomic level. Typically, the fisheries economics takes the harvesters' individual profit or private rent as the economic goal and maximizes it to analyze bio-economic interactions between harvester's fishing behaviour, stock regulation and one or two commercially important species [1]-[4]. While this tradition allows clear focus on particular fisheries issues, such as efficient utilization of commercial fish stocks, it limits itself to partial equilibrium analysis of capture fisheries only and thus loses insights into macroeconomic consequence [5].

As fisheries regulation moves towards alleviating social and ecological problems, there is a growing need to assess the full impact of regulation on the economy. In this sense, the full economic contribution of capture fisheries, or more specifically the economy-wide value added induced by fish harvesting activity, lies not only in the harvesting industry itself, but also (and perhaps more importantly) in its effects on secondary activities such as fish processing and fish marketing, and in its indirect impact upon non-fisheries sectors. Although there is no official data directly showing these multiplicative effects, FAO [6] estimate that each employment in capture fisheries and aquaculture production generates about four employments in secondary activities related to the sector.

In the economics literature, disaggregated computable general equilibrium (CGE) models are a popular tool to empirically conduct economy-wide analysis, as these are able to summarize the full structural responses of the economy to a change in an economic component like capture fisheries. However, CGE models are dependent upon the constraints of standard neoclassical economic theory, involve complicated construction procedures, and have not yet been widely used in fisheries economic analysis [7]. A conventional alternative to the CGE models is the input-output method. This describes the general quantitative interdependence of an economic system and has the simplicity in mathematics and operation.

Seung and Waters [8] and Placenti [9] reviewed the input-output methods used for fisheries management in the US and in Europe respectively. The majority of the applications date from the 1970s and 1980s (US) and up to the late 1990s (Europe). They were all based on the traditional Leontief demand-driven input-output model, where final demands in the fisheries sectors were taken as exogenous variables driving the input-output economic system. These researches can normally account for three types of fishing activity effects; direct, open-complete and closed-complete effect. The direct effect is measured in terms of the value added directly by fish harvesting activity, which is also basically the classical fisheries economists' primary interest-individual profit or private rent. The open-complete effect is measured in terms of the value added generated in other sectors due to their response to changes in the demand or supply of capture fisheries. This effect is modelled in the standard Leontief demand-driven input-output model and captured through the Leontief inverse, (which measures total direct and indirect impacts of a change in final demands on total outputs of the sectors). The closedcomplete effect is measured in terms of the value added generated in all sectors due to their response to the demand or supply of capture fisheries as well as their response to the change in household consumption induced by income generation. This effect is modelled in an extended Leontief demand-driven input-output model, where household consumption is transformed from exogenous to endogenous variable, and captured through the extended Leontief inverse that measures total direct, indirect and induced impacts of a change in final demands (excluding household consumption) on total outputs of the sectors. However, the economy-wide impact of capture fisheries based on demand-driven input-output models is now seen as unsatisfactory, partly because of its inconsistency with fisheries regulation schemes.

Conventionally, fisheries regulation focuses on supply side controls with a variety of regulatory instruments such as gear and fleet control, entry limitation, seasonal closing, capacity buy-back, total allowable catch (TAC), individual transferable quota (ITQ), marine protected area (MPA), etc. While the TAC or ITQ target output control, the majority of the other instruments target fishing effort control. Recent research tends to use an "output supply-driven" input-output method to measure the economic impact of catch or quota regulations on capture fisheries. The "output supply-driven" method typically partitions the input-output structure into two blocks, one representing the fisheries under output control and another representing the rest of the economy driven by conventional final demands. In the model the final demands of the fisheries block are endogenous and the final demands of the rest of the economy block are often assumed to be zero in order to separate the impact of fisheries output control. The model is not completely based on either the Leontief [10] [11] or the Ghosh model [12], but relies on the Leontief production or the Ghosh allocating coefficients to measure backward or forward linkage effects, respectively [13].

The "output supply-driven" method was initially proposed to study impacts of different farm types in agricul- 
ture [14]. Leung and Pooley [15] and Cai et al. [16] adopted the method to study the economic linkage impact of the longline fisheries in Hawaii. At the same time in Europe, within the PECHDEV project, a group of researchers in France, United Kingdom, Denmark, Italy and Spain extended the analysis from input-output into a SAM (Social Accounting Matrix) framework in order to measure the regional economic consequences of coastal ecosystem change [17]. In that context, Fernandez-Macho et al. [18] used the SAM of the Spanish region of Galicia (one of the main fishing regions in Europe) to measure the economic impacts of TAC regulation of hake on the regional economy. The advantage of their research is that it internalized the income distribution, consumption and employment factors. Seung and Waters [19] subsequently followed the approach of Fernandez-Macho et al. [18] in studying the economic linkages of Alaska fisheries.

In contrast to the traditional interest of fisheries economics in the microeconomic consequences of fishing effort regulation, and the recent applications of the "output supply-driven" method to measure the macroeconomic impact of fish output regulation, there is a lacuna in the literature regarding the macroeconomic impact of fishing effort regulation. In this paper, we attempt to fill this gap by developing a method to measure the economy-wide impact of fishing effort control. Combining input-output techniques with industrial evolutionary theory, we take capture fisheries as the "carrier sector", which produces the "core inputs" - the fish — that constitutes one of the fundamental forces driving the fisheries economy. Instead of using exogenous fisheries outputs, we follow the Ghosh supply-driven model and take primary inputs in capture fisheries as the exogenous driving variables. This allows the forward linkage impact of capture fisheries on the other fisheries sectors to be measured. We view the non-fisheries sector to be the backward linkage sector of the fisheries sector and employ the Leontief demand-driven model to measure the backward linkage impact of the fisheries sector on the non-fisheries sector. Thus, the model developed in this research is a combination of the Ghosh supply-driven model and the Leontief demand-driven model.

This paper is organised as follows. Section 2 discusses the structure of a fisheries economy, based on a fish chain and sector linkage approach. Section 3 deals with methodological issues, discussing the existing studies in the area - and then presents the proposed model. Section 4 provides an application of the model to the Thai fisheries in the Gulf of Thailand. Finally, Section 5 concludes.

\section{The Structure of a Fisheries Economy: A Fish Chain and Sector Linkage Approach}

A fisheries economy basically refers to the coastal or small island economy in which the fisheries sector constitutes a base industry and where changes therein could have dramatic implications for the whole economy [20]. Nowadays, as the relative importance (in terms of GDP, employment, contribution to exports etc.) of the marine fisheries industry is diminishing in developed countries, the 'fisheries economy' mainly refers to the coastal or small island economies in developing countries where reliance on the fisheries remains strong. Figure 1 depicts the macroeconomic structure of a fisheries economy where the fisheries sector is treated separately in parallel to the rest of the economy, as well as to the foreign economy. Both fisheries and non-fisheries sectors require resource, factor and commodity inputs to produce fisheries and non-fisheries products, respectively. The direct link between the fisheries and non-fisheries sector relates to intermediate commodity use. While production in the fisheries sector clearly needs to use non-fisheries product inputs such as food, tools, energy, etc., fisheries products are also needed in production of some non-fisheries sectors such as animal feeds, the food industry, the pharmaceutical industry, etc. Fish products are also final products for human consumption.

In input-output literature on industrial linkages, sectors are interlinked with each other; a sector is viewed as the backward linkage (or upstream) sector of another if its product is used in another sector's production-with the sector that uses its product referred to as the forward linkage (or downstream) sector [21]. The sectors that have larger than average linkage indices are referred as the "key sectors". This approach relies largely on the quantitative data showing industrial interrelationships (typically the input-output coefficients), but ignores the real causal relationship behind the numbers. In real cases, a sector can affect another but may not, in turn, be affected by change in the other. According to industrial evolutionary theory [22] [23], different sectors may play different roles in industrial formation and development; there are some "core inputs" that trigger industrial evolution and the sectors producing these core inputs are the "carrier sectors or branches". Thus, only the "carrier sectors" can affect the sectors that use the "core inputs" and not vice versa.

In the case of fisheries, Figure 1 shows that fisheries affect the rest of the economy in three ways. First, fisheries require the direct use of intermediate non-fisheries products and thus stimulate the rest of the economy, by 


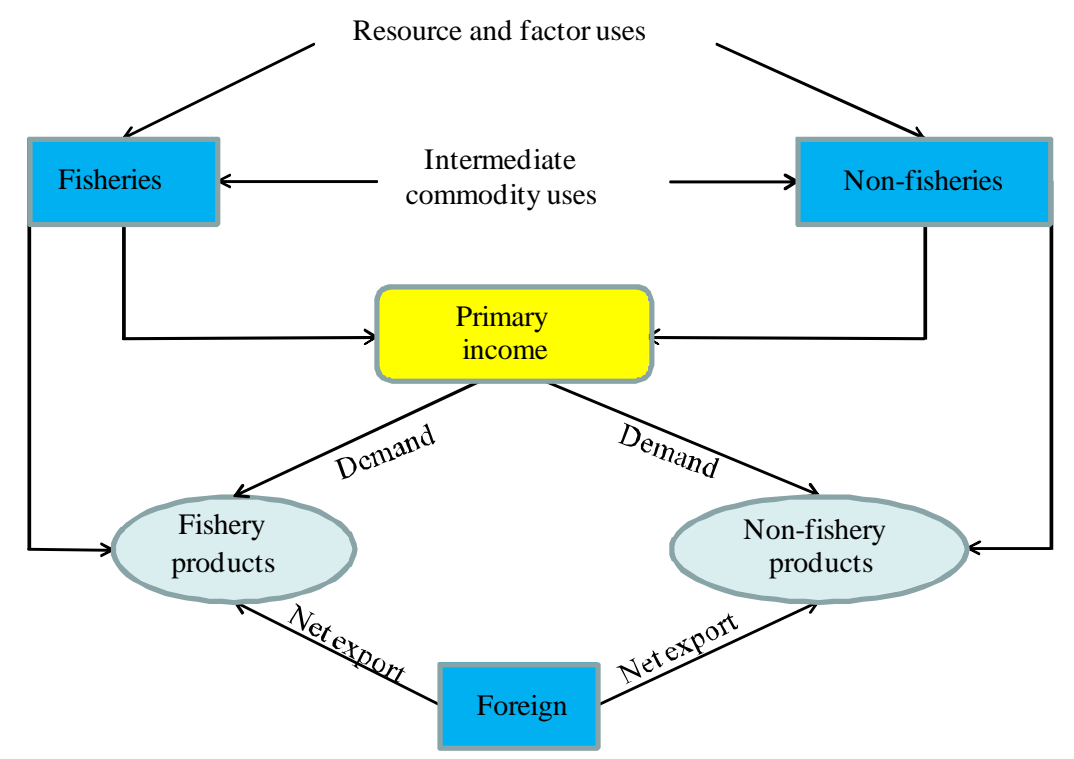

Figure 1. Macroeconomic structure of fishery economy.

creating a backward linkage effect. Second fisheries provide employment and generate primary income-labour and capital incomes, which in turn finances consumption and investment, and thus indirectly stimulates the rest of the economy by creating a base-sector effect. Finally, fisheries products can be exported and thus increase local export revenues by creating a trade effect.

Fisheries production has two effects on the demand side-it can affect the intermediate demand of non-fisheries sectors and/or the final demand of consumers for fisheries products. However, as fisheries are a primary industry that depends on the aquatic resources available (or the abundance of certain fish stocks), its production is not fully flexible to meet whatever demands for fish ensue, and so most current fisheries regulation sets out stock constraints (Total allowable catches) to restrict fisheries production. Thus, it is better to view current fisheries practices as principally determined on the supply side (depending on the situation of fish stocks).

Within the fisheries sector, we encounter a number of sub-sectors such as fish producing, processing and marketing. These sectors are linked through their products, with Figure 2 illustrating the linkage among the fisheries sub-sectors. Fish production includes capture fisheries and aquaculture-and the products are raw and fresh fish; part of which will directly go to households for consumption, part of which will go to the fish market for sale, and the rest of which will go to the fish processing sub-sector for processing. Following industrial evolutionary theory, we can regard raw and fresh fish to be the "core inputs" of the fish processing and marketing sub-sectors, and so we can regard capture fisheries and aquaculture as the "carrier sectors or branches". Fish processing produces processed fish; part of which will directly go to households for consumption, part of which will go to the fish marketing sub-sector for sale. Finally, raw and/or fresh and/or processed fish can also be supplied direct to the consumers.

The fisheries sub-sectors can be further disaggregated. Capture fisheries can be subdivided by type of fish harvesters (for example, artisanal and industrial harvesters), by scale, by type of boat and/or gear, or by metier (a combination of boat, gear and targeted species). Similarly, aquaculture firms can be distinguished by size and/or the species they farm. Within the fish processing sub-sector, fish processing firms can be divided according to processing methods used (such as frozen, smoking, canned, salted, etc). Finally, the fish marketing sub-sector can be split into different types of traders (such as international traders, wholesalers, fishmongers/retailers), or into different sales chains, or into domestic, regional and international destinations, etc. In reality, the linkages among the different fisheries sub-sectors can be complex, as Figure 3 shows in the case of the Gulf of Thailand fisheries sector.

Since there is no foreign fleet fishing in Thai waters, about $80 \%$ of the total landings come from domestic industrial/commercial fisheries (2109 kt/year). Domestic artisanal landings (527) kt/year) were mostly for local consumption and traditional processing (fish sauce, salted, steamed/smoked, shrimp paste and others including fish ball/cracker) and sold through local fish mongers. About one-third of commercial catches directly go to 


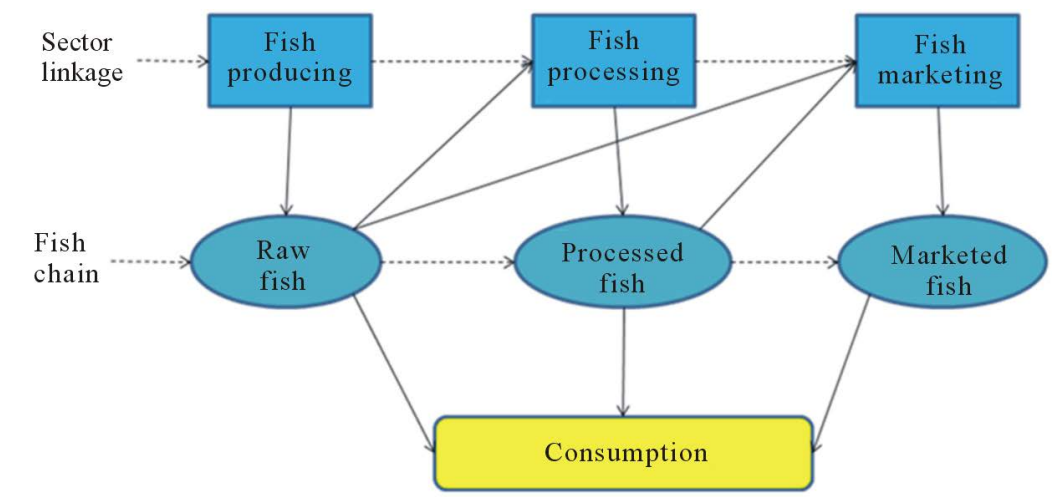

Figure 2. The structure of fishery industry.

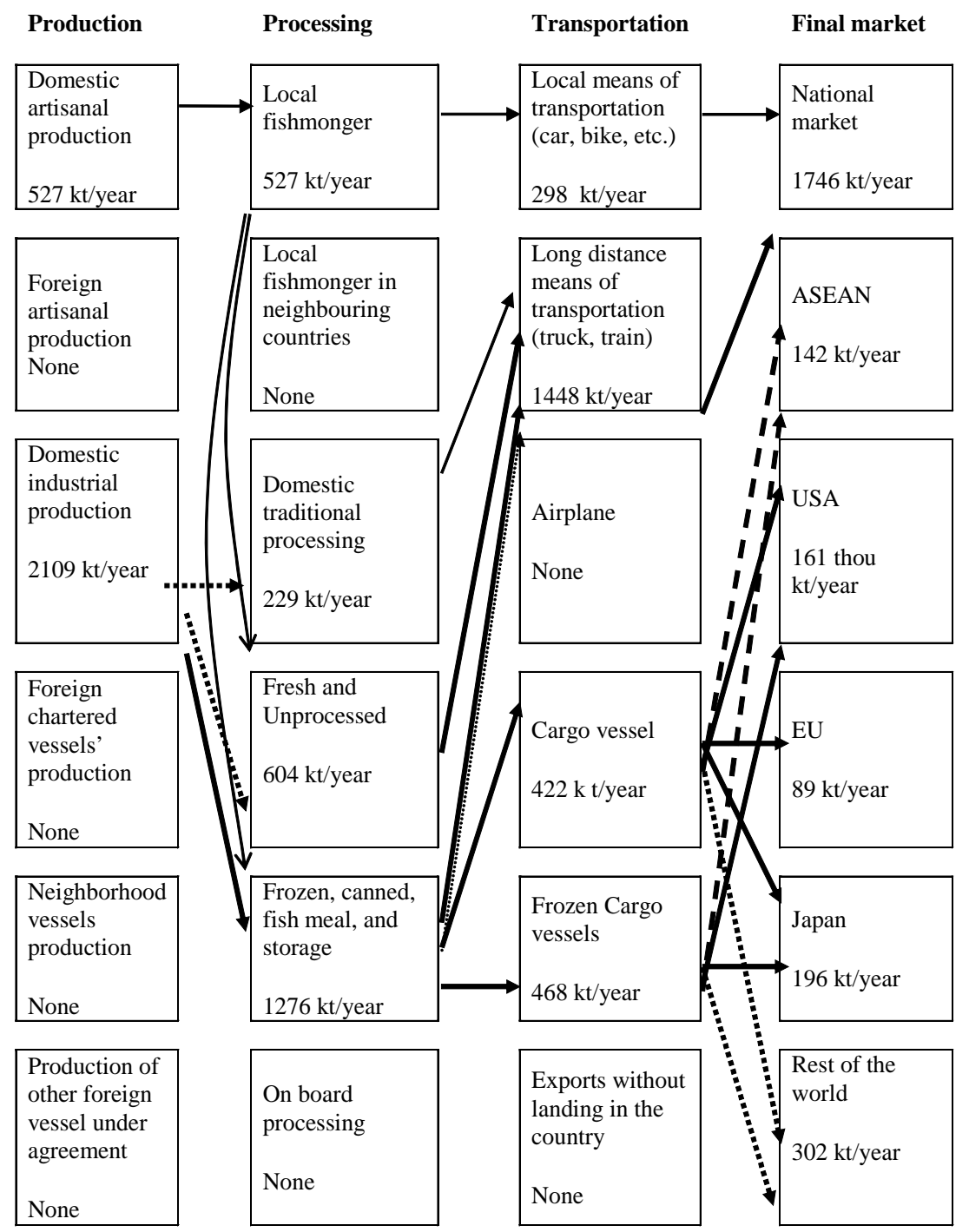

Figure 3. Thai fish chain and fishery linkage in 2004 (live weight equivalent).

domestic consumer markets, and the rest to the processing sector. Over $50 \%$ of commercial catches are frozen and canned, and exported through cargo vessels or supplied to the national market via long distance transportation. 


\section{Methodology}

The Leontief and Ghosh models are constructed on basis of input-output table and its transpose, respectively. Our model combines both types of the conventional input-output models and thus requires creation of a hybrid input-output table. Assume there are $n$ industries each of which produces a single commodity in the economy. And let $i$ and $j$ represent the commodity and industry, respectively. Table 1 illustrates the conventional input-output table that the Leontief model is based on. In the table, $a_{i j}$, known as the Leontief production coefficients or the input-output coefficients, is the proportion of industry i's product in industry $j$ 's total production use; $a_{i, j}=\frac{x_{i, j}}{X_{j}}$, where $x_{i, j}$ is sector $j$ 's production requirement on sector $i$ 's product; final use, $Y_{i}$, is the exogenous variable driving the Leontief model to derive total output, $X_{i}$ (which is identical to total input or outlay, $X_{j}$ ); and primary input, $V_{j}$, is not relevant in the model. Table 2 illustrates the transposed input-output table that the Ghosh model is based on. In the table, $b_{j, i}=\frac{x_{j, i}}{X_{i}}$, known as the Ghosh allocating coefficients, is the share of the commodity $i$ allocated to sector $j$ in total commodity $i$; primary input here is the exogenous variable driving the Ghosh model to derive total input; and final use is not relevant in the model.

The hybrid input-output table developed in this research distinguishes industry (or commodity) into two types, namely fishery and non-fishery industry, which are denoted by $f$ and $n f$, respectively. From Table 3 , we can see that both the Leontief production and the Ghosh allocation coefficients appear in the table. While the former are set up for non-fishery industry, the latter are for fishery industry or commodity. Our task is to consolidate these two into a unique framework. Now, let us present the model in detail.

Consider a fisheries economy with a general economic structure that includes a fish harvesting sector ( $f h$ ) which consists of $n$ harvesters, a fish processing sector ( $f p)$, a fish marketing sector ( $f m$ ), and a non-fisheries sector $(n f)$. Following fisheries economic theory, fish harvesters make production decisions based on fishing effort, which can be represented in various terms by primary inputs. Assuming that fish harvesters' production follows the Ghosh supply-driven model, where exogenous primary inputs determine total inputs (through the Ghosh intermediate allocating coefficients), then the supply and demand balances of the harvesting products are as follows:

Table 1. The input-output table for the Leontief model.

\begin{tabular}{cccc}
\hline & Industry & Final use & Total output \\
\hline Commodity & $a_{i, j}$ & $Y_{i}$ & $X_{i}$ \\
Primary input & $V_{j}$ & & \\
Total input & $X_{j}$ & \\
\hline
\end{tabular}

Table 2. The transposed input-output table for the Ghosh model.

\begin{tabular}{cccc} 
& Commodity & Primary input & Total input \\
\hline Industry & $b_{j, i}$ & $V_{j}$ & $X_{j}$ \\
Final use & $Y_{i}$ & & \\
Total output & $X_{i}$ & \\
\hline
\end{tabular}

Table 3. The hybrid input-output table for the present model.

\begin{tabular}{cccc}
\hline & Fishery commodity & Non-fishery commodity & Primary input \\
\hline Fishery industry & $b_{f, f}$ & $a_{f, n f}$ & $V_{f}$ \\
Non-fishery industry & $b_{n f, f}$ & $a_{n f, n f}$ & $V_{n f}$ \\
Final use & $Y_{f}$ & $Y_{n f}$ & \\
Total output & $X_{f}$ & $X_{n f}$ & \\
\hline
\end{tabular}




$$
B_{f h, f} \cdot X_{f}+a_{f h, n f} \cdot X_{n f}+V_{f h}=X_{f h}, \quad f \in(f h, f p, f m) \text { and } f h \in(1, \cdots, n)
$$

where, as defined in Table 3, $f$ and $n f$ indicate fisheries and non-fisheries sectors, respectively; $B_{f h, f}$ is a parameter matrix of the Ghosh intermediate allocating coefficients with elements $b_{f h, f}$ that supplies the proportion of fisheries sector $f$ 's product allocated to harvester $f h ; X_{f}$ is a column vector of all fisheries sectors' total outputs; $a_{f h, n f}$ is the Leontief intermediate use coefficients that produces the proportion of non-fisheries sector's product used by harvester $f h$ for fishing; $X_{n f}$ is non-fisheries sector's total input; $V_{f h}$ is a column vector of exogenous primary inputs (or value added of harvesters), and $X_{f h}$ is a column vector of endogenous total inputs of harvesters that equals the sum of intermediate inputs plus primary inputs or value added.

The primary input of the fish processing sector depends on the amount of fish harvested. The more raw and fresh fish that are to be processed, the more primary inputs that are needed in the fish processing sector. As a result, the production of the fish processing sector will also follow the Ghosh supply-driven model with the following supply and demand balance:

$$
B_{f p, f} \cdot X_{f}+a_{f p, n f} \cdot X_{n f}+V_{f p}=X_{f p}
$$

where $B_{f p, f}$ is a row vector of the Ghosh intermediate allocating coefficients of all fisheries sectors for the fish processing sector. Its element $b_{f p, f}$ indicates the proportion of fisheries sector $f$ 's product allocated to the fish processing sector (reflecting the forward linkage effect). $a_{f p, n f}$ is the Leontief intermediate use coefficient indicating the proportion of non-fisheries sector's product used by fish processing. The primary input (or value added) of the sector is endogenously determined through the 'pushing' effect of capture fisheries.

The primary input of the fish marketing sector depends on both the amount of fish harvested and processed. The more raw or processed fish that needs to be distributed in the market, the more the primary input needed in the fish marketing sector. As a result, the production of the fish marketing sector also follows the Ghosh supply-driven model, with the following supply and demand balance:

$$
B_{f m, f} \cdot X_{f}+a_{f m, n f} \cdot X_{n f}+V_{f m}=X_{f m}
$$

where $B_{f m, f}$ is a row vector of the Ghosh intermediate allocating coefficients of all sectors for the fish marketing sector. Its element $b_{f m, f}$ indicates the proportion of fisheries sector $f$ 's product allocated to the fish marketing sector (reflecting the forward linkage effect). $a_{f m, n f}$ is the Leontief intermediate use coefficient indicating the proportion of non-fisheries sector's product used by fish marketing. The primary input (or value added) of the sector is endogenously determined through the 'pushing' effect of both fish harvesting and fish processing.

Contrary to the supply-driven fisheries sectors, the non-fisheries sector is demand-driven. It must meet both the intermediate requirements of the fisheries sectors and the final demand of society. The production of the non-fisheries sector follows the Leontief demand-driven model and has the following material balance:

$$
A_{n f, f} \cdot X_{f}+a_{n f, n f} \cdot X_{n f}+D_{n f}=X_{n f}
$$

where $A_{n f, f}$ is a row vector of the Leontief intermediate use coefficients of the non-fisheries sector. Its element $a_{n f, f}$ indicates the proportion of the non-fisheries sector's product used in fisheries sector $f$ 's production (reflecting the backward linkage effect). $a_{n f, n f}$ is the Leontief intermediate use coefficient indicating the proportion of non-fisheries sector's use of its own product. $D_{n f}$ is exogenous final demand for non-fisheries product. The first and second items on the left hand side of this equation describe the total intermediate demand by the fisheries sectors for products from the non-fisheries sector, while the third item shows total final demand by the fisheries sector for non-fisheries products.

The value added generated by the fish processing sector is "pushed" by the harvesting sub-sector, and its computation relies on a new parameter rather than completely on the input-output table:

$$
c_{f p} \cdot B A_{f p, f} \cdot X_{f}=V_{f p}
$$

where the new parameter, $c_{f p}$, is the ratio of value added to total core input in the fish processing sector, representing the effect of per unit core input use on value added generation. $B A_{f p, j}$ is a row vector of the Ghosh intermediate allocating coefficients of fish harvesters for the fish processing sector. It differs from $B_{f p, f}$ in that its elements $b_{f p, f p}$ and $b_{f p, f m}$ are all zero.

The value added generated by the fish marketing sector is "pushed" by both the fish harvesting and fish processing sub-sectors, and its computation relies on a new parameter rather than completely on the input-output table: 


$$
c_{f m} \cdot B A_{f m, f} \cdot X_{f}=V_{f m}
$$

where the new parameter, $c_{f m}$, is the ratio of value added to total core input in the fish marketing sector, representing the effect of per unit of core input use on value added generation. $B A_{f m, f}$ is a row vector of the Ghosh intermediate allocating coefficients of the fish harvesting and fish processing sectors. It differs from $B_{f m, f}$ in that its elements of $b_{f m, f m}$ is zero.

Since non-fisheries production follows the Leontief demand model, its value added will be determined endogenously by total output or input:

$$
v_{n f} \cdot X_{n f}=V_{n f}
$$

where $v_{n f}$ represents the share of value added in total input in the non-fisheries sector.

Finally all sectors' value added should be summed to produce total economy-wide value added, which is equivalent to the total final demand of society (GDP).

$$
\sum_{f} V_{f}+V_{n f}=V
$$

Combining Equations (1)-(8), and letting $\tilde{A}, \tilde{Y}$ and $\tilde{X}$ denote coefficients matrix, exogenous and endogenous variable vectors, respectively, a consolidated matrix presentation is obtained:

$$
\tilde{A} \cdot \tilde{X}+\tilde{Y}=\tilde{X}
$$

where

$$
\tilde{A}=\left(\begin{array}{ccc}
B_{f, f} & A_{f, n f} & I_{f, f+n f+1} \\
A_{n f, f} & a_{n f, n f} & O_{n f, f+n f+1} \\
O_{f h, f} & O_{f h, n f} & O_{f h, f+n f+1} \\
B A_{f p, f} & O_{f p, n f} & O_{f p, f+n f+1} \\
B A_{f m, f} & O_{f m, n f} & O_{f m, f+n f+1} \\
O_{1, f} & V_{1, n f} & O_{1, f+n f+1} \\
O_{1, f} & O_{1, n f} & V_{1, f+n f+1}
\end{array}\right), \quad \tilde{X}=\left(\begin{array}{c}
X_{f} \\
X_{n f} \\
O_{f h} \\
V_{f p} \\
V_{f m} \\
V_{n f} \\
V
\end{array}\right) \text { and } \tilde{Y}=\left(\begin{array}{c}
V_{f h} \\
O_{f p+f m} \\
D_{n f} \\
O_{f+n f+1} \\
\sum_{f h} V_{f h}
\end{array}\right)
$$

and

$$
B_{f, f}=\left(\begin{array}{c}
B_{f h, f} \\
B_{f p, f} \\
B_{f m, f}
\end{array}\right), \quad A_{f, n f}=\left(\begin{array}{c}
A_{f h, n f} \\
A_{f p, n f} \\
A_{f m, n f}
\end{array}\right) \text {, and } V_{1, f+n f+1}=\left(O_{1, f h}, 1,1,1,0\right) \text { is specially defined there. }
$$

The solution of this linear equation system can be solved with

$$
\tilde{X}=(I-\tilde{A})^{-1} \cdot \tilde{Y}
$$

where $I_{2(f+n f)+1,2(f+n f)+1}$ is the conventional unity matrix.

This equation describes an economic system where exogenous primary inputs of fish harvesting (or fishing effort in the terminology of fisheries economics) determines fish production, these act as core inputs to generate value added in the fish processing, fish trading and non-fisheries sectors (linkage sectors). In addition, the overall value added generated in the fisheries sectors will be linked to the total final demand of the fisheries sector. Thus, an overall economic effect-that includes both production and consumption side effects of capture fisheries-can be obtained.

In the inverse matrix, $(I-\tilde{A})^{-1}$, some rows capture the overall effect of the exogenous fishing efforts and non-fisheries demand on total production of economic sectors, and some other rows capture the overall effect on value-added generation. One point is worth to note that the Equation (10) does not describe a simultaneous linear equation system. In fact, while Equations (1)-(4) need to be solved simultaneously, Equations (5)-(8) can be solved sequentially. The presentation of Equation (10) just provides a convenient way to solve the system. 


\section{An Application to the Fisheries in the Gulf of Thailand}

The fisheries sector plays an important role in the Thai economy, directly contributing about 2\% of GDP. Fishing grounds within Thailand's EEZ are located in the Gulf of Thailand (GoT) and in the Andaman Sea, with just over two-thirds of the 2004 catch (2.5 million tonnes-worth US\$8 billion) landed in the Gulf and the remainder taken from the Andaman Sea. The main catches are pelagic fish (33\%), followed by "trash" (29\%) and demersal fish (18\%). Other species caught include other food fish, squid and cuttlefish, shrimp, crab, mollusc and other (mainly jellyfish), but these are in small volumes. Due to over fishing, especially in the GoT, catches have stagnated in recent years. As a consequence, large vessels in the Thai fleet ( $>18$ metres long) have been fishing on non-Thai fishing grounds_-in the EEZs of nearby coastal states along the Indian and Atlantic Ocean coastlines.

Thai fisheries, like other tropical fisheries, are multi-fleet, multi-gears and multi-species. The fleet comprises six main vessel types (trawlers, purse seiners, gill netters, falling netters, other mobile netters, and hook and liners), with trawlers accounting for $63 \%$ of catch, purse seiners $29 \%$, and other fleets $8 \%$. In contrast, while the total number of registered vessels was 16,432, just 39\% (6439 vessels) were trawlers and 10\% (1699 vessels) purse seiners. In the trawler fleet, three types of trawl (otter board, pair, and beam) are used. The most important are the small otter-board trawl (18 m or less), with a limited capacity, which fish mainly in Thai waters. Larger otter-board trawls do fish outside Thai waters, as do the (usually) larger commercial pair trawlers. Beam trawlers are small, some converting from small otter board trawl in an effort to reduce fishing costs. The otter board trawl is a demersal fishing gear, and 36\% of its catches are demersal fish (mainly big eyes, threadfin bream, lizard fish, crocker, red snapper, and ray), 33\% are trash fish (including low quality catches not for human consumption and juveniles of economic species caught as by-catch), and the remainder are pelagic fish, cephalopods, other food fish-and small quantities of shrimp and crab. The purse seiner fleet uses two main gears: purse seines for targeting various pelagic fish, and anchovy purse seines-which specifically fish for anchovy. While the former are large fishing vessels and (some) fish outside Thai waters, anchovy purse seine fishes are restricted to Thai fishing grounds. In 2004, anchovy catches amounted to 129,000 tons, or about $22 \%$ of purse seiner catches from the Gulf of Thailand.

Disaggregating the 2004 catch by gear type sees otter board trawlers account for 52\%, followed by $23 \%$ for purse seiners, $11 \%$ for pair trawlers, and $6 \%$ for anchovy purse seiners. Catches by other fishing gears accounted for $1 \%$ or less.

Laloe [24] has identified a number of principal metiers employed in the Thai fishery using the framework advanced by Pech [25], where a metier refers to the activities of a particular fleet, equipped with a particular gear, and targeting a particular species as main catch (although other species may be ensnared as by-catch). Our research focuses on the two most common metiers employed in the GoT fishery-the "Otter board trawler" and the "Anchovy purse seiner" (all the other vessel and gear types are conflated as "Other harvesters”). In order to connect the metiers with macroeconomic structure, we combine fisheries data, national accounting data and input-output table for Thailand in 2004 to compile a compact input-output table with details of the fisheries sector (Table 4).

It can be seen from the Table that capture fisheries in the Gulf of Thailand contribute $0.077 \%$ of GDP, slightly higher than the share $(0.069 \%)$ from capture fisheries in areas other than the Gulf of Thailand and from aquaculture. The fish processing and fish trading sectors contribute $4.36 \%$ and $4.71 \%$ to GDP, respectively, while the non-fisheries sector contributes nearly $90 \%$ of GDP. The shares of total output are similar to the GDP shares, suggesting that capture fisheries sector in the Gulf of Thailand (and indeed elsewhere) contribute only negligibly to the Thai national economy. However, when the sector's linkage effects are considered, we see fisheries exerting a much more important role in the economy. Fish processing and trading sectors completely depend on capture fisheries and aquaculture and each of them contributes nearly 5\% of GDP, reflecting the multiplier effect of fisheries.

Our analysis now compares a Business As Usual (BAU) scenario with 12 alternative scenarios to examine how different levels of fishing effort would affect the economy. In scenarios 1 - 4 each scenario assumes fishing effort of each of the four harvesters (otter board trawl, anchovy seine, other harvesters, other fishing) increases by one million US\$-and shows the corresponding changes produced in value added in the fish processing, fish trading and non-fisheries sectors (the multiplier effect of fishing effort on those sectors). Scenarios 5 - 8 consider the impact of fishing regulation on the economy-and presumes that the regulations introduced cause the fishing effort of each harvester to be reduced by 10\%. Scenarios 9 - 12 explore extreme cases when fisheries are completely removed out of the economy so as to illustrate the national importance of fisheries. 
Table 4. Thai input-output table: Fisheries (2004).

\begin{tabular}{|c|c|c|c|c|c|c|c|c|c|c|c|}
\hline $\begin{array}{c}\text { Transposed Thai } \\
\text { Input-output table } \\
\text { (million US\$ at } 2004 \\
\text { price) }\end{array}$ & $\begin{array}{l}\text { Otter } \\
\text { board } \\
\text { trawler }\end{array}$ & $\begin{array}{l}\text { Anchovy } \\
\text { purse } \\
\text { seiner }\end{array}$ & $\begin{array}{c}\text { Other } \\
\text { harvesters }\end{array}$ & $\begin{array}{l}\text { Other } \\
\text { fishing }\end{array}$ & $\begin{array}{c}\text { Fish } \\
\text { processing }\end{array}$ & $\begin{array}{l}\text { Fish } \\
\text { trading }\end{array}$ & Non-fishery & $\begin{array}{c}\text { Sum of } \\
\text { intermediate } \\
\text { use }\end{array}$ & $\begin{array}{l}\text { Value } \\
\text { added }\end{array}$ & $\begin{array}{l}\text { Total } \\
\text { input }\end{array}$ & $\begin{array}{l}\text { Share of } \\
\text { value } \\
\text { added (\%) }\end{array}$ \\
\hline $\begin{array}{l}\text { Otter board trawler in } \\
\text { GOT }\end{array}$ & 0 & 0 & 0 & 7 & 7 & 0 & 53 & 67 & 67 & 133 & $0.02 \%$ \\
\hline $\begin{array}{l}\text { Anchovy purse seiner } \\
\text { in GOT }\end{array}$ & 0 & 0 & 0 & 1 & 1 & 0 & 12 & 15 & 15 & 29 & $0.01 \%$ \\
\hline $\begin{array}{c}\text { Other harvesters in } \\
\text { GOT }\end{array}$ & 0 & 0 & 0 & 205 & 205 & 0 & 1641 & 2051 & 2051 & 4102 & $0.74 \%$ \\
\hline Other fishing & 0 & 0 & 0 & 191 & 191 & 0 & 1532 & 1915 & 1915 & 3830 & $0.69 \%$ \\
\hline Fish processing & 80 & 1 & 2225 & 2549 & 1214 & 0 & 6070 & 12,140 & 12,140 & 24,280 & $4.36 \%$ \\
\hline Fish trading & 19 & 10 & 558 & 626 & 12950 & 0 & 12,889 & 27,052 & 13,111 & 40,164 & $4.71 \%$ \\
\hline Non-fishery & 0 & 0 & 0 & 0 & 0 & 0 & 244,888 & 244,888 & 249,117 & 494,004 & $89.48 \%$ \\
\hline $\begin{array}{c}\text { Sum of intermediate } \\
\text { product }\end{array}$ & 99 & 11 & 2784 & 3581 & 14568 & $\mathbf{0}$ & 267,084 & 288,127 & 278,415 & 566,542 & $100.00 \%$ \\
\hline Final product & 34 & 18 & 1318 & 249 & 9712 & 40,164 & 226,920 & 278,415 & & & \\
\hline Total output & 133 & 29 & 4102 & 3830 & 24,280 & 40,164 & 494,004 & 566,542 & & & \\
\hline Output share (\%) & $0.02 \%$ & $0.01 \%$ & $0.72 \%$ & $0.68 \%$ & $4.29 \%$ & $7.09 \%$ & $87.20 \%$ & $100.00 \%$ & & & \\
\hline
\end{tabular}

Table 4 and Table 5 show the resultant value added of the 12 scenarios in value and percentage terms respectively. It is clear from scenarios 1 - 4 in Table 5 that a one million dollar increase in the effort of Otter board trawlers in the GoT will induce a nearly three million dollar increase in the fish processing and fish marketing sectors, and a five million dollar increase in the non-fisheries sector. In total this 1 million dollar increase in effort adds about 12 million dollars to GDP. In terms of employment, as one employment on an Otter board trawler can generate around three employments in each of the fish processing and fish marketing sectors, and five employments in the non-fisheries sector, the effort increase creates around an extra 12 jobs economy-wide. As can be seen (scenarios 1 - 4), Anchovy purse seiner operations in the GoT have the smallest multiplier effect on GDP (US\$ 3.5 million), other harvesters in GoT have a similar effect on GDP to that of the Otter board trawler; while other fishing activities (aquaculture and fishing outside the Gulf of Thailand) has the largest effect on GDP (US\$ 15 million). In each case, the (backward linkage) effect on the non-fisheries sector (penultimate column) is larger than the (forward linkage) effect on fish processing and trading, as the backward linkage effect on the non-fishing sector combines all the effects of fish harvesting, processing and trading as well as society's final demand. Table 6, however, shows that this one million dollar increase in fishing effort of each capture fisheries in GoT will affect GDP negligibly in percentage terms.

Scenarios 5 - 8 (Table 5) shows that a 10\% limitation in fishing effort of each harvester will, through the multiplier, reduce outputs of the fish processing, fish trading and non-fisheries sectors. In GDP terms, Table 6 shows that $10 \%$ limitation in fishing effort of Otter board trawler in GoT will reduce GDP by $0.03 \%$, the effect from Anchovy purse seiner is negligible, the effect from the other harvester in GoT by $0.8 \%$, and the effect from other fishing by $1 \%$.

What would happen if some of harvesters are completely removed from action? Scenario 9 in Table 5 and Table 6 suggests that if all Otter board trawlers cease all operation, it will induce a loss in value added in the fish processing, fish trading and non-fisheries sectors of $0.15 \%, 0.15 \%$ and $0.13 \%$, respectively and overall will cause GDP to decline by $0.28 \%$. If all anchovy purse seiners cease operation (Scenario 10), its effects on value added are relatively small-losses of $0.03 \%, 0.08 \%$ and $0.03 \%$ for fish processing, fish trading and non-fisheries sectors, respectively (GDP falls by just $0.02 \%$ ). However, when all fishers in the GoT halt fishing activities, losses in value-added in the fish processing and trading sectors are over $43 \%$, although the impact on the non-fisheries sector will be relatively small (slightly less than 4\%). However, GDP drops sharply—by over $8 \%$. In the most extreme case (scenario 12), if all Thai fisheries ceased, so would activities in the fish processing and trading sectors, value-added in the non-fisheries sector's value will drop by nearly 9\%., and GDP would slump by over $18.5 \%$. 
Table 5. Scenario analysis on impact of fishing effort regulation on the Thai economy (value).

\begin{tabular}{|c|c|c|c|c|c|c|c|c|c|c|c|c|c|}
\hline & $\begin{array}{l}\text { Changes in } \\
\text { value added }\end{array}$ & $\begin{array}{c}\text { Scenario } \\
1\end{array}$ & $\begin{array}{c}\text { Scenario } \\
2\end{array}$ & $\begin{array}{c}\text { Scenario } \\
3\end{array}$ & $\begin{array}{c}\text { Scenario } \\
4\end{array}$ & $\begin{array}{c}\text { Scenario } \\
5\end{array}$ & $\begin{array}{c}\text { Scenario } \\
6\end{array}$ & $\begin{array}{c}\text { Scenario } \\
7\end{array}$ & $\begin{array}{c}\text { Scenario } \\
8\end{array}$ & $\begin{array}{c}\text { Scenario } \\
9\end{array}$ & $\begin{array}{c}\text { Scenario } \\
10\end{array}$ & $\begin{array}{c}\text { Scenario } \\
11\end{array}$ & $\begin{array}{c}\text { Scenario } \\
12\end{array}$ \\
\hline \multirow[t]{4}{*}{$\begin{array}{l}\text { Exogenous } \\
\text { change }\end{array}$} & $\begin{array}{l}\text { Otter board } \\
\text { trawler in } \\
\text { GOT }\end{array}$ & 1.00 & 0.00 & 0.00 & 0.00 & -6.65 & 0.00 & 0.00 & 0.00 & -66.54 & 0.00 & -66.54 & -66.54 \\
\hline & $\begin{array}{l}\text { Anchovy } \\
\text { purse seiner } \\
\text { in GOT }\end{array}$ & 0.00 & 1.00 & 0.00 & 0.00 & 0.00 & -1.46 & 0.00 & 0.00 & 0.00 & -14.56 & -14.56 & -14.56 \\
\hline & $\begin{array}{c}\text { Other } \\
\text { harvesters in } \\
\text { GOT }\end{array}$ & 0.00 & 0.00 & 1.00 & 0.00 & 0.00 & 0.00 & -205.08 & 0.00 & 0.00 & 0.00 & -2050.81 & -2050.81 \\
\hline & Other fishing & 0.00 & 0.00 & 0.00 & 1.00 & 0.00 & 0.00 & 0.00 & -191.48 & 0.00 & 0.00 & 0.00 & -1914.82 \\
\hline \multirow[t]{4}{*}{$\begin{array}{l}\text { Endogenous } \\
\text { change }\end{array}$} & $\begin{array}{c}\text { Fish } \\
\text { procession }\end{array}$ & 2.76 & 0.22 & 2.49 & 3.58 & -18.34 & -0.32 & -509.95 & -685.41 & -183.42 & -3.15 & -5286.04 & -12140.19 \\
\hline & Fish trading & 2.97 & 0.75 & 2.69 & 3.86 & -19.74 & -1.09 & -550.91 & -739.41 & -197.37 & -10.90 & -5717.35 & -13111.40 \\
\hline & Non-fishery & 5.03 & 1.52 & 4.61 & 6.47 & -33.45 & -2.21 & -945.61 & -1238.36 & -334.53 & -22.08 & -9812.74 & -22196.31 \\
\hline & $\begin{array}{l}\text { Change in } \\
\text { GDP }\end{array}$ & 11.75 & 3.48 & 10.78 & 14.91 & -78.19 & -5.07 & -2211.55 & -2854.66 & -781.85 & -50.69 & -22948.04 & -51494.62 \\
\hline
\end{tabular}

Table 6. Scenario analysis on impact of fishing effort regulation on the Thai economy (\%).

\begin{tabular}{|c|c|c|c|c|c|c|c|c|c|c|c|c|c|}
\hline & $\begin{array}{l}\text { Changes in } \\
\text { value added }\end{array}$ & $\begin{array}{c}\text { Scenario } \\
1\end{array}$ & $\begin{array}{c}\text { Scenario } \\
2\end{array}$ & $\begin{array}{c}\text { Scenario } \\
3\end{array}$ & $\begin{array}{c}\text { Scenario } \\
4\end{array}$ & $\begin{array}{c}\text { Scenario } \\
5\end{array}$ & $\begin{array}{c}\text { Scenario } \\
6\end{array}$ & $\begin{array}{c}\text { Scenario } \\
7\end{array}$ & $\begin{array}{c}\text { Scenario } \\
8\end{array}$ & $\begin{array}{c}\text { Scenario } \\
9\end{array}$ & $\begin{array}{c}\text { Scenario } \\
10\end{array}$ & $\begin{array}{c}\text { Scenario } \\
11\end{array}$ & $\begin{array}{c}\text { Scenario } \\
12\end{array}$ \\
\hline \multirow[t]{4}{*}{$\begin{array}{l}\text { Exogenous } \\
\text { change }\end{array}$} & $\begin{array}{l}\text { Otter board } \\
\text { trawler in } \\
\text { GOT }\end{array}$ & $1.503 \%$ & $0.000 \%$ & $0.000 \%$ & $0.000 \%$ & $-10 \%$ & $0 \%$ & $0 \%$ & $0 \%$ & $-100 \%$ & $0 \%$ & $-100 \%$ & $-100 \%$ \\
\hline & $\begin{array}{l}\text { Anchovy } \\
\text { purse seiner in } \\
\text { GOT }\end{array}$ & $0.000 \%$ & $6.868 \%$ & $0.000 \%$ & $0.000 \%$ & $0 \%$ & $-10 \%$ & $0 \%$ & $0 \%$ & $0 \%$ & $-100 \%$ & $-100 \%$ & $-100 \%$ \\
\hline & $\begin{array}{c}\text { Other } \\
\text { harvesters in } \\
\text { GOT }\end{array}$ & $0.000 \%$ & $0.000 \%$ & $0.049 \%$ & $0.000 \%$ & $0 \%$ & $0 \%$ & $-10 \%$ & $0 \%$ & $0 \%$ & $0 \%$ & $-100 \%$ & $-100 \%$ \\
\hline & Other fishing & $0.000 \%$ & $0.000 \%$ & $0.000 \%$ & $0.052 \%$ & $0 \%$ & $0 \%$ & $0 \%$ & $-10 \%$ & $0 \%$ & $0 \%$ & $0 \%$ & $-100 \%$ \\
\hline \multirow[t]{4}{*}{$\begin{array}{l}\text { Endogenous } \\
\text { change }\end{array}$} & $\begin{array}{c}\text { Fish } \\
\text { procession }\end{array}$ & $0.023 \%$ & $0.002 \%$ & $0.020 \%$ & $0.029 \%$ & $-0.15 \%$ & $0.00 \%$ & $-4.20 \%$ & $-5.65 \%$ & $-1.51 \%$ & $-0.03 \%$ & $-43.54 \%$ & $-100.00 \%$ \\
\hline & Fish trading & $0.023 \%$ & $0.006 \%$ & $0.020 \%$ & $0.029 \%$ & $-0.15 \%$ & $-0.01 \%$ & $-4.20 \%$ & $-5.64 \%$ & $-1.51 \%$ & $-0.08 \%$ & $-43.61 \%$ & $-100.00 \%$ \\
\hline & Non-fishery & $0.002 \%$ & $0.001 \%$ & $0.002 \%$ & $0.003 \%$ & $-0.01 \%$ & $0.00 \%$ & $-0.38 \%$ & $-0.50 \%$ & $-0.13 \%$ & $-0.01 \%$ & $-3.94 \%$ & $-8.91 \%$ \\
\hline & $\begin{array}{l}\text { Change in } \\
\text { GDP }\end{array}$ & $0.004 \%$ & $0.001 \%$ & $0.004 \%$ & $0.005 \%$ & $-0.03 \%$ & $0.00 \%$ & $-0.79 \%$ & $-1.03 \%$ & $-0.28 \%$ & $-0.02 \%$ & $-8.24 \%$ & $-18.50 \%$ \\
\hline
\end{tabular}

\section{Conclusions}

This research bridges the gap between fisheries microeconomic regulation and its macroeconomic impact. It has elaborated the sectoral linkage between the fisheries and non-fisheries sectors and the fish chain from harvesting to processing and marketing, connecting "bottom-up" capture fisheries to "top-down” economic structure. Based on this approach, a new input-output linkage model has been developed to measure the multiplier effect of a change in fishing effort of bottom-up harvesters on the whole economy. As the fisheries sector is a primary industry whose production critically depends on the aquatic resource, we use industrial evolutionary theory to qualitatively specify causal relationships among the sectors, and suggest that the fisheries sectors follow the Ghosh supply-driven model while the non-fisheries sector follows the Leontief demand-driven model. This differs greatly from conventional input-output linkage models where interrelationships among sectors are mechanically identified, completely relying on input-output account data. We believe in this way the economywide impact of capture fisheries can be better measured.

Thus the model innovatively combines both the Ghosh supply-driven model and the Leontief demand-driven model into a unique model framework. To our knowledge, this appears novel in input-output economics literature. The model is constructed in a concise and operational mathematical format, and can be readily applied with 
qualitative specification on industrial interrelations and moderate data requirements on a fisheries input-output table. However, because the required table normally does not exist, one first needs to compile it by inserting fisheries microeconomic data. This involves a considerable effort in disaggregating the fisheries sector, connecting it to the other economic sectors, and ensuring consistency.

The empirical findings based on the Thai fisheries corroborate findings in other literature regarding the fourfold multiplier effect of capture fisheries on the fish processing and trading sectors. However, our results also reveal that capture fisheries make a much greater contribution to the economy than is traditionally thought. As we show, a US\$1 million increase in fishing effort applied within most fisheries can generate as much as a ten times increase in the value of GDP. On the other hand, if particular fisheries (such as the Otter board trawler and the Anchovy purse seiner) are regulated to protect fish stocks, economic losses are relatively modest—unless all fisheries operations cease, when GDP will drop by around one-fifth.

The present research may be advanced further in a number of directions. One avenue is to study dynamic change in the impact multipliers of capture fisheries in response to change in fish stocks, so that fisheries can be managed more effectively. A second avenue would be to analyse the economic impact of policies that emphasize maximising fish quality and value-added across the fish chain, as opposed to maximising production. In that way, it can be possible to extend considerably the economic outcomes of fisheries and their impact on the economy.

\section{Acknowledgements}

This work was carried out with financial support from the Commission of the European Communities, specific RTD Programme "International Research in Co-operation” (INCO-DEV), “Ecosystems, Societies, Consilience, Precautionary Principle: Development of an assessment method of the societal cost for best fishing practices and efficient public policies” (ECOST).

\section{References}

[1] Gordon, H. (1954) The Economic Theory of a Common-Property Resource: The Fishery. Journal of Political Economy, 62, 124-142. http://dx.doi.org/10.1086/257497

[2] Schaefer, M. (1957) Some Considerations of Population Dynamics and Economics in Relation to the Management of the Commercial Marine Fisheries. Journal of the Fisheries Research Board of Canada, 14, 669-681. http://dx.doi.org/10.1139/f57-025

[3] Clark, C. and Munro, G. (1975) The Economics of Fishing and Modern Capital Theory: A Simplified Approach. Journal of Environmental Economics and Management, 2, 96-106. http://dx.doi.org/10.1016/0095-0696(75)90002-9

[4] Bjorndal, T. and Conrad, J. (1987) Capital Dynamics in the North Sea Herring Fishery. Marine Resource Economics, 4, 63-74.

[5] Failler, P. and Pan, H. (2007) A Computable General Equilibrium (CGE) Model in Fisheries: Policy Analysis with Evidence from Five European Regions. Final Scientific Report, EU Funded RTD Project QLRT-2000-02277 PECHDEV, $72 \mathrm{p}$.

[6] FAO (2012) The State of the World Fisheries and Aquaculture. Rome, $230 \mathrm{p}$.

[7] Pan, H., Failler, P. and Floros, C. (2007) A Regional Computable General Equilibrium Model for Fisheries. CEMARE Research Paper P163, 46 p. http://www.port.ac.uk/research/cemare/publications/researchpapers

[8] Seung, C. and Waters, E. (2006) A Review of Regional Economic Models for Fisheries Management in the U.S. Marine Resource Economics, 21, 101-124.

[9] Placenti, V. (2003) Input/Output Method Presentation. In: Failler, P., Ed., Assessment Method Reviews; Economics, Ecology and Biology Frameworks; Regional expectancies; Case Study Presentations, Report No. 1, European Union Research Project QLRT-2000-02277, CEMARE, University of Portsmouth, Portsmouth, 40-82.

[10] Ten Raa, T. (2005) The Economics of Input-Output Analysis. Cambridge University Press, Cambridge.

[11] Leontief, W., et al. (1953) Studies in the Structure of the American Economy. Oxford University Press, Oxford.

[12] Ghosh, A. (1958) Input-Output Approach to an Allocation System. Economica, 25, 58-64. http://dx.doi.org/10.2307/2550694

[13] Cai, J. and Leung, P. (2004) Linkage Measures: A Revisit and a Suggested Alternative. Economic System Research, 16, 65-85. http://dx.doi.org/10.1080/0953531032000164800

[14] Johnson, T. and Kulshreshtah, S. (1982) Exogenizing Agriculture in an Input-Output Model to Estimate Relative Im- 
pact of Different Farm Types. Western Journal of Agricultural Economics, 7,187-198.

[15] Leung, P. and Pooley, S. (2002) Regional Economic Impacts of Reductions in Fisheries Production: A Supply-Driven Approach. Marine Resource Economics, 16, 251-262.

[16] Cai, J., Leung, P., Pan, M. and Pooley, S. (2005) Economic Linkage Impacts of Hawaii’s Longline Fishing Regulations. Fisheries Research, 74, 232-242. http://dx.doi.org/10.1016/j.fishres.2005.02.006

[17] Failler, P., Ed. (2004) Static CGEM, Biological Model and SAM Presentations. PECHDEV Report No. 2, European Union Research Project QLRT-2000-02277, CEMARE, University of Portsmouth, Portsmouth, 231 p.

[18] Fernandez-Macho, J., Gallastegui, C. and Gonzalez, P. (2008) Economic Impacts of TAC Regulation: A SupplyDriven SAM Approach. Fisheries Research, 90, 225-234. http://dx.doi.org/10.1016/j.fishres.2007.10.019

[19] Seung, C. and Waters, E. (2009) Measuring the Economic Linkage of Alaska Fisheries: A Supply-Driven Social Accounting Matrix (SDSAM) Approach. Fisheries Research, 97, 17-23. http://dx.doi.org/10.1016/j.fishres.2008.12.013

[20] Agnarson and Arnason (2007) The Role of the Fishing Industry in the Icelandic Economy. In: Bjorndal, et al. Eds., Advances in Fisheries Economics, Blackwell Publishing. http://dx.doi.org/10.1002/9780470751589

[21] Hirschman, A. (1958) The Strategy of Economic Development. Yale University Press, New Haven.

[22] Perez, C. (1983) Structural Change and the Assimilation of New Technologies in the Economic and Social System. Futures, 15, 357-375. http://dx.doi.org/10.1016/0016-3287(83)90050-2

[23] Freeman, C. and Loucã, F. (2001) As Time Goes by. OUP, Oxford.

[24] Laloe, F. (2009) Conceptual Model of the Ecosystem-Society Interactions. ECOST Project Report D2.3. www.ecostproject.org

[25] Pech, N., et al. (2001) Fitting a Model of Flexible Multifleet-Multispecies Fisheries to Senegalese Artisanal Fishery Data. Aquatic Living Resource, 14, 81-98. http://dx.doi.org/10.1016/S0990-7440(01)01108-1 